\title{
Increased levels of XPA might be the basis of cisplatin resistance in germ cell tumours
}

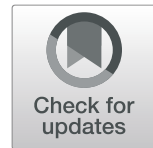

\author{
Zuzana Cierna ${ }^{1 \dagger}$, Vera Miskovska ${ }^{2,3 \dagger}$, Jan Roska ${ }^{4 \dagger}$, Dana Jurkovicova ${ }^{4 \dagger}$, Lucia Borszekova Pulzova ${ }^{4 \dagger}$, \\ Zuzana Sestakova ${ }^{4}$, Lenka Hurbanova ${ }^{4}$, Katarina Machalekova ${ }^{3}$, Michal Chovanec ${ }^{5,6}$, Katarina Rejlekova ${ }^{3,5}$, \\ Daniela Svetlovska ${ }^{3,7}$, Katarina Kalavska ${ }^{3,7,8}$, Karol Kajo ${ }^{3}$, Pavel Babal ${ }^{1,9}$, Jozef Mardiak ${ }^{3,5}$, Thomas A. Ward ${ }^{10}$, \\ Michal Mego ${ }^{4,5,6,7 \dagger}$ and Miroslav Chovanec ${ }^{4^{*}+}$ (D)
}

\begin{abstract}
Background: Germ cell tumours (GCTs) represent a highly curable malignity as they respond well to cisplatin (CDDP)-based chemotherapy. Nevertheless, a small proportion of GCT patients relapse or do not respond to therapy. As this might be caused by an increased capacity to repair CDDP-induced DNA damage, identification of DNA repair biomarkers predicting inadequate or aberrant response to CDDP, and thus poor prognosis for GCT patients, poses a challenge. The objective of this study is to examine the expression levels of the key nucleotide excision repair (NER) factors, XPA, ERCC1 and XPF, in GCT patients and cell lines.

Methods: Two hundred seven GCT patients' specimens with sufficient follow-up clinical-pathological data and pairwise combinations of CDDP-resistant and -sensitive GCT cell lines were included. Immunohistochemistry was used to detect the ERCC1, XPF and XPA protein expression levels in GCT patients' specimen and Western blot and qRT-PCR examined the protein and mRNA expression levels in GCT cell lines.
\end{abstract}

Results: GCT patients with Iow XPA expression had significantly better overall survival than patients with high expression (hazard ratio $=0.38,95 \%$ confidence interval: $0.12-1.23, p=0.0228$ ). In addition, XPA expression was increased in the non-seminomatous histological subtype, IGCCCG poor prognosis group, increasing $S$ stage, as well as the presence of lung, liver and non-pulmonary visceral metastases. Importantly, a correlation between inadequate or aberrant CDDP response and XPA expression found in GCT patients was also seen in GCT cell lines.

Conclusions: XPA expression is an additional independent prognostic biomarker for stratifying GCT patients, allowing for improvements in decision-making on treatment for those at high risk of refractoriness or relapse. In addition, it could represent a novel therapeutic target in GCTs.

Keywords: Germ cell tumours, DNA repair, Nucleotide excision repair, XPA, Prognostic marker

\section{Background}

Germ cell tumours (GCTs) represent the most chemosensitive solid malignancy; up to $70-80 \%$ of patients with metastatic disease can be cured with the first-line standard-dose cisplatin (CDDP)-based chemotherapy. Nevertheless, $20-30 \%$ of patients relapse or do not

\footnotetext{
*Correspondence: miroslav.chovanec@savba.sk

†Zuzana Cierna, Vera Miskovska, Jan Roska, Dana Jurkovicova, and LuciaBorszekova Pulzova, have contributed equally to this manuscript. ${ }^{+}$Michal Mego and Miroslav Chovanec are co-senior authors of the study. ${ }^{4}$ Department of Genetics, Cancer Research Institute, Biomedical Research Center, University Science Park for Biomedicine, Slovak Academy of Sciences, Bratislava, Slovakia

Full list of author information is available at the end of the article
}

respond to therapy $[1,2]$. About $20-25 \%$ of relapsed patients may be cured with salvage conventional or highdose chemotherapy [1,3-5]. However, patients who fail to be cured with salvage chemotherapy have a poor prognosis $[6,7]$.

The main pharmacological target of CDDP is DNA, and therefore DNA alterations represent the key factor determining toxicity. CDDP induces a variety of DNA damage lesions, including DNA interstrand cross-links (ICLs) [8]. ICLs activate the DNA damage response (DDR) and ICL repair pathways, the latter being a highly complex process that involves coordinated action of several DNA repair mechanisms [9], including nucleotide

(c) The Author(s). 2020 Open Access This article is distributed under the terms of the Creative Commons Attribution 4.0 International License (http://creativecommons.org/licenses/by/4.0/), which permits unrestricted use, distribution, and 
excision repair (NER) pathway. NER employs some 30 DNA repair proteins [10] and mechanistically contributes to ICL repair by mediating lesion recognition and incision. Central to DNA lesion recognition is the xeroderma pigmentosum complementation group A (XPA) protein, which also functions in the DNA lesion verification step and assembly of the NER incision complexes [11]. Incision is mediated by the two structure-specific nucleases, xeroderma pigmentosum complementation group F and G (XPF and XPG, respectively), the former forming a complex with the excision repair crosscomplementation group 1 (ERCC1) protein. ERCC1 per se is catalytically inactive and serves to target XPF to different substrates, thereby regulating its availability and activity [12].

Correlation between the chemosensitivity and expression level of the NER factors has attracted research attention. Up-regulation of the NER proteins in tumours has repeatedly been associated with a worse prognosis with decreased ERCC1 mRNA/protein levels leading to an improved response to CDDP-based chemotherapy, and survival, in patients with metastatic lung cancer [13], head and neck squamous cell carcinoma [14], as well as of ovarian [15], gastric [16] and bladder cancers [17]. In GCTs, however, data are far from consistent. While ERCC1 expression has been shown to correlate with CDDP sensitivity in GCTs [18], no association with patient survival [18] or clinical-pathological features (tumour size and clinical stage) [19] has been reported. Furthermore, XPA expression was shown to be highly heterogeneous, with no significant difference detected between CDDP-sensitive tumours and refractory disease. Interestingly, teratomas (TE), and refractory tumours resected in relapse after chemotherapy, have been shown to be strongly XPA positive [20]. In GCT-derived cell lines, no correlation between XPA expression and sensitivity to CDDP has been observed and it was therefore concluded that, for patients with newly diagnosed GCTs, XPA detection has no prognostic or predictive value, as it does not play a critical role in overall resistance to treatment [20]. Notably, in vitro cell culture data showed that XPA, ERCC1 and XPF levels are generally lower in GCT cell lines than in cell lines from other tumour types $[21,22]$.

In this study, we have examined the expression levels of the ERCC1, XPF and XPA proteins in GCT patients and correlated these with clinical-pathological characteristics and therapy outcomes to examine whether increased expression might be associated with inferior survival. We show that the ERCC1, XPF and XPA protein levels are significantly higher in GCTs compared to normal testicular tissues and we report an inverse correlation between XPA expression and prognosis in GCT patients. We demonstrate that an increase of the combined expression of the NER proteins (ERCC1, XPF and XPA) also associates with worse overall survival (OS). We propose that increased XPA expression, and to a lesser extent of the combined NER, in primary GCTs might facilitate treatment resistance as a consequence of increased DNA repair capacity. Hence, we suggest that NER, particularly XPA, could represent a novel promising therapeutic target in GCTs.

\section{Methods}

\section{Patients and cell lines}

The present study (Protocol IZLO1, Chair: M. Mego) included 207 GCT patients treated between 1999 and 2013 in the National Cancer Institute and/or St. Elisabeth Cancer Institute, Bratislava, Slovakia, with available paraffin-embedded tumour tissue specimen and sufficient follow-up clinical data. Patients with concurrent malignancy other than non-melanoma skin cancer in the previous 5 years were excluded.

NTERA-2 cl.D1 [NT2/D1] cell line is commercially available (ATCC ${ }^{\ominus}$ CRL-1973 $^{\mathrm{mm}}$ ). The remaining GCT cell lines, H12.1, H12.1D, H12.1ODM, 2102EP, 1411HP and 1777NRpmet, were kindly provided by Dr. Thomas Mueller, Martin Luther University Halle-Wittenberg, Halle (Saale), Germany [23-27]. CDDP-sensitive (H12.1 and 2102EP) and -resistant (H12.1ODM, 1411HP and 1777NRpmet) GCT cell lines were grown in RPMI-1640 medium supplemented with $5 \%$ fetal bovine serum (FBS), penicillin (100 units/ml) and streptomycin $(10 \mu \mathrm{l} /$ $\mathrm{ml}$ ). NTERA-2 cl.D1 (NT2/D1) GCT cell line was grown in Dulbecco's modified eagle's medium supplemented with F-10 nutrient mixture (1:1), 5\% FBS, penicillin (100 units $/ \mathrm{ml})$ and streptomycin $(10 \mu \mathrm{l} / \mathrm{ml})$. Cell lines were cultivated at $37^{\circ} \mathrm{C}$ in $5 \% \mathrm{CO}_{2}$ atmosphere.

\section{CDDP treatment}

H12.1, H12.1ODM, 1411HP and 1777NRpmet GCT cell lines were cultivated as described above. When the cell cultures reached approximately $80 \%$ confluency, cultivation medium was replaced with fresh medium containing $17 \mu \mathrm{M}$ CDDP. After $2 \mathrm{~h}$ treatment, the cells were washed three times with phosphate-buffered saline (PBS) and collected by scrapping.

\section{Tumour pathology}

Pathology review was conducted by two pathologists from the Department of Pathology, Faculty of Medicine, Comenius University, Bratislava, Slovakia.

\section{Diagnosis and tissue samples}

Where available, both tumour and normal testicular tissues were evaluated. The study included tumour specimens from 207 GCT patients before administration of systemic therapy; 200 cases of primary gonadal and 7 
cases of extragonadal tumours (5 retroperitoneal and 2 mediastinal). GCTs were classified according to World Health Organization criteria [28]. Normal testicular tissues from non-cancer patients were not available, and therefore normal tissues adjacent to tumours were used (49 samples), as previously described [29, 30].

\section{Tissue microarray construction}

One or two representative tumour areas from each histological subtype of GCTs were identified on H\&E sections. Samples from normal testicular tissue were also marked, where available. Sections were matched to their corresponding paraffin blocks (donor blocks), and 3-mm diameter tissue cores were removed from these donor blocks with the multipurpose sampling tool Harris UniCore and inserted into the recipient master block. Recipient blocks were cut into $5-\mu \mathrm{m}$ sections, which were transferred onto coated slides.

\section{Immunohistochemical staining}

Slides were deparaffinized and rehydrated in $10 \mathrm{mM}$ PBS ( $\mathrm{pH}$ 7.2). The tissue epitopes were unmasked using the Dako PT Link automated water bath heating process. The slides were incubated in Tris-EDTA retrieval solution (10 mM Tris, $1 \mathrm{mM}$ EDTA pH 9.0) (ERCC1 and XPF staining) or citrate retrieval buffer of pH 6.0 (XPA staining) at $98^{\circ} \mathrm{C}$ for $20 \mathrm{~min}$. The slides were subsequently incubated for $1 \mathrm{~h}$ at room temperature (RT) with the primary mouse monoclonal antibody against ERCC1 (Dako, clone 4F9), mouse monoclonal antibody against XPF (Abcam [SPM228]: ab17798) or mouse monoclonal antibody against XPA (Abcam [12F5]: ab2352) diluted 1: 100 in Dako REAL antibody diluent (Dako) and immunostained using anti-mouse/anti-rabbit immunoperoxidase polymer (EnVision FLEX/HRP, Dako) at RT for $30 \mathrm{~min}$, according to the manufacturer's instructions. For visualization, the slides were treated with diaminobenzidine substrate-chromogen solution (DAB, Dako) for $5 \mathrm{~min}$. Finally, the slides were counterstained with haematoxylin. Appendix or tonsil tissue samples were used as positive controls for ERCC1 or XPA and XPF, respectively. The same tissues with omitted primary antibodies served as a negative control.

\section{Immunohistochemical stain scoring}

Tumour cores were independently assessed by two pathologists who were blinded to the clinical-pathological data. In cases of disagreement, a consensus was found. The expression levels of the NER proteins were scored by a weighted histoscore (HS), which accounts for both the extent of cell staining and the staining intensity [31]. The percentage of positively stained cells was calculated and the average intensity of positively stained cells was given a score from 0 to $3(0=$ no staining, $1=$ weak, $2=$ intermediate and $3=$ strong staining). The HS was then calculated by multiplying the percentage score by the intensity score, to yield a minimum value of 0 and a maximum value of 300 . If multiple histological subtypes were present in a sample, the greater HS was taken. Based on the HS, the NER protein expression levels were graded as "low" $(\leq 150)$ or "high" ( $>150)$. The combined NER expression level was calculated as sum of weighted HS for each individual NER protein to yield a minimum value of 0 and a maximum value of 900 . In a similar manner to the expression level of each individual NER protein, the combined NER expression level was graded as "low" ( $\leq 450)$ or "high" (> 450).

\section{mRNA expression evaluation}

Total RNA was extracted using TRI Reagent solution (Life Technologies) and quantified using MaestroNano Spectrophotometer (Applied Biological Materials Inc.) and Qubit fluorometer (Qubit ${ }^{\circ}$ RNA HS Assay Kit, Life Technologies). Differential expression of the XPA, ERCC1 and XPF genes was evaluated by qRT-PCR. Briefly, cDNA was synthesized, using First-Strand cDNA Synthesis System from Central European Biosystems, from $1.5 \mu \mathrm{g}$ of total RNA in $20 \mu \mathrm{l}$ reactions containing $2 \mu \mathrm{l}$ of $10 \mathrm{x}$ MuLV buffer, $1 \mu \mathrm{M}$ of $\mathrm{p}(\mathrm{dN}) 6$ primer, 0.1 mM of dNTP mix and 100 units of MuLV reverse transcriptase. These were incubated at $42{ }^{\circ} \mathrm{C}$ for $1 \mathrm{~h}$ followed by enzyme inactivation at $95^{\circ} \mathrm{C}$ for $5 \mathrm{~min}$. Real-time PCR detection and quantification of XPA, XPF and ERCC1 expression was performed using SYBR Premix Ex Taq II (Tli RNaseH Plus), ROX plus (Takara) and primers listed in Additional file 1: Table S1. Ct values were normalized against the $P G K 1$ reference gene, which is stably expressed across all GCT cell lines tested.

\section{Protein expression evaluation}

Protein expression analyses were performed using cell lysates prepared in ice-cold RIPA buffer $(50 \mathrm{mM}$ Tris$\mathrm{HCl}, \mathrm{pH}$ 7.5; $150 \mathrm{mM} \mathrm{NaCl} ; 5 \mathrm{mM}$ EDTA; $1 \%$ Triton X100; $0.5 \%$ NaDOC; $0.1 \%$ SDS) containing MS-SAFE Protease and Phosphatase Inhibitor (Sigma Aldrich). Primary antibodies against XPA, phosphorylated XPA at S196 [pXPA(S196)] and XPF were purchased from Thermo Fisher Scientific. The ERCC1 antibody was obtained from Santa Cruz Biotechnology. The clarified protein lysates were diluted in 5x SDS-PAGE sample loading buffer (250 mM Tris. $\mathrm{HCl}, \mathrm{pH} 6.8,10 \%$ SDS, 30\% (v/v) glycerol, $10 \mathrm{mM}$ DTT, 0.05\% (w/v) bromophenol blue), boiled at $95^{\circ} \mathrm{C}$ for $10 \mathrm{~min}$, and resolved on MiniPROTEAN $^{\circ}$ TGX Stain-Free ${ }^{\mathrm{Tm}}$ Precast Gels (BioRad) at $120 \mathrm{~V}$. To quantify total protein, gels were activated by exposure to ultraviolet light (UV; $302 \mathrm{~nm}$ ) for $5 \mathrm{~min}$ and visualized using an Amersham Imager 600 (GE Healthcare). The resolved proteins were transferred onto 
Amersham Protean $0.1 \mu \mathrm{m}$ nitrocellulose membrane (Sigma Aldrich) in transfer buffer $(25 \mathrm{mM}$ Tris base, $190 \mathrm{mM}$ glycine, $20 \%$ methanol) at $70 \mathrm{~V}$ in a wet blotting apparatus for $1 \mathrm{~h}$ at $4{ }^{\circ} \mathrm{C}$. The membrane was blocked with 5\% skimmed milk powder diluted in Tris-buffered saline (TBS; $10 \mathrm{mM}$ Tris base, $\mathrm{pH} 7.4 ; 150 \mathrm{mM} \mathrm{NaCl}$ ) at RT for $1 \mathrm{~h}$. Membranes were incubated with primary antibodies diluted in $2.5 \%$ skimmed milk in TTBS (TBS containing $0.05 \%$ Tween 20) [anti-XPA 1: 1,000; antipXPA(S196) 1: 500; anti-XPF 1: 1,000 and anti-ERCC1 1:750] at RT for $1 \mathrm{~h}$ with shaking and washed twice in TTBS for $5 \mathrm{~min}$. The membrane was then incubated with goat anti-mouse HRP-conjugated secondary antibody (1: 20,000) (Santa Cruz Biotechnology) at RT for 1 $\mathrm{h}$ with shaking. The protein bands were visualized using SuperSignal ${ }^{\mathrm{Tm}}$ West Femto Maximum Sensitivity chemiluminescence substrate (Thermo Fisher Scientific) and the Odyssey Fc Imaging System (Li-COR). Protein quantification was performed using the Li-COR Image Studio software normalized to the total protein content.

Quantification of pXPA(S196) expression was performed by dot blot analysis. In a typical dot blot experiment, $20 \mu \mathrm{g}$ of protein extract were mixed with an equal volume of nanopure $\mathrm{H}_{2} \mathrm{O}$ and blotted onto pre-wetted Immobilon-FL membrane (Sigma Aldrich) $(0.8 \mu \mathrm{l} / \mathrm{dot})$ and allowed to dry. After re-wetting in methanol, the membrane was stained with REVERT total protein stain (Li-COR) and then imaged with the Odyssey ${ }^{\circ} \mathrm{Fc}$ Imaging System in the $700 \mathrm{~nm}$ channel. The membrane was then washed with TBS and blocked for $1 \mathrm{~h}$ in TTBS containing $2 \%$ albumin. The blot was incubated at $4{ }^{\circ} \mathrm{C}$ overnight with the pXPA(Ser196) primary antibody diluted 1:500, followed by $2 \mathrm{~h}$ in secondary antibody, goat anti-rabbit HRP-conjugated antibody $(1: 20,000)$, and chemiluminescence detection (SuperSignal ${ }^{\mathrm{m}}$ West Femto Maximum Sensitivity Substrate). Dot blots were analyzed using Li-COR Image Studio software. For quantification, intensity of each dot obtained by chemiluminescence was normalized to the $700 \mathrm{~nm}$ intensity of the corresponding sample, representing the total protein content.

\section{Statistical analysis}

Since the distribution of weighted HS for expression of the NER proteins was significantly different from the normal distribution (the Shapiro-Wilk test), we used non-parametric tests for analyses. Analyses of differences in distributions of the expression levels of the NER proteins between the two groups of patients were performed using the Mann-Whitney $U$ test, while multiple groups were compared by the Kruskal-Wallis test.

Median follow-up period was calculated as a median observation time among all patients and among those still alive at the time of their last follow-up. OS was calculated from the date of orchiectomy or tumour biopsy to the date of death or last follow-up. OS was estimated using the Kaplan-Meier product limit method and compared by the log-rank test. All reported $p$ values were two-sided. Statistical analyses were performed using NCSS 11 statistical analysis software (J. Hintze, Kaysville, Utah, USA).

For statistical analysis of the mRNA and protein expression data, SigmaPlot 12.5 was used. Normality of distribution was tested by the Shapiro-Wilk and Kolmogorov-Smirnov tests. Relative quantification of the mRNA expression was calculated with $2^{-\Delta \Delta C t}$ method, which represents relative fold changes of the mRNA expression. Therefore, $\Delta \Delta \mathrm{Ct}=\Delta \mathrm{Ct}$ (CDDP-resistant cell line) - $\Delta$ Ct (CDDP-sensitive cell line). Analysis of the significance of fold change in the mRNA expression between the studied groups was applied to the $\Delta \mathrm{Ct}$ values. If normally distributed, mRNA and protein expression data were tested by the Student's t-test or analysis of variance (ANOVA) with the Bonferroni's or Tukey's test for multiple comparisons. The non-parametric MannWhitney Rank Sum test and the Kruskal-Wallis One Way ANOVA with the Tukey's test for multiple comparisons were used for non-normally distributed data. All tests were two-tailed, performed at the significance level $\alpha=0.05$.

For all analyses, $p<0.05$ was considered statistically significant $\left(" p<0.05 ;{ }^{* *} p<0.01,{ }^{* * * *} p<0.005\right)$.

\section{Results}

\section{The expression of the NER proteins in GCT patients}

Patients' characteristics are summarized in Additional file 2: Table S2. The majority of patients had non-seminomatous primary testicular tumour and a good prognosis according to the IGCCCG risk group. All patients were treated with CDDP-based chemotherapy. Tumour specimens included 38 pure seminomas and 169 non-seminomas.

We observed significantly higher expression of all three evaluated NER proteins in GCTs in comparison to normal testicular tissues (Table 1). The highest XPA and $E R C C 1$ expression was found in TE, with decreasing amounts in yolk sac tumours and choriocarcinoma. In contrast, lowest expression was detected in seminoma and embryonal carcinoma. Interestingly, while XPF expression was considerably higher than ERCC1 or XPA expression (in both tumourous and normal tissue) there was no significant difference in XPF expression across all GCT histological subtypes (Table 1).

Correlation between expression of individual NER proteins and clinical-pathological characteristics is shown in Table 2. The expression levels of all three NER proteins were higher in non-seminomas compared to seminomas, although for $E R C C 1$ the difference was not statistically significant. Higher XPA expression was observed in patients with more advanced disease including IGCCCG 
Table 1 The expression of the NER proteins in different histological subtypes of primary GCTs $(n=207)$

\begin{tabular}{|c|c|c|c|c|c|c|c|c|c|c|c|c|c|}
\hline \multirow[b]{2}{*}{ Histological subtype } & \multirow[b]{2}{*}{$N$} & \multicolumn{4}{|l|}{ ERCC1 } & \multicolumn{4}{|l|}{$\mathrm{XPF}$} & \multicolumn{4}{|l|}{ XPA } \\
\hline & & Mean HS & SEM & Median & $\overline{p \text { value }^{a}}$ & Mean HS & SEM & Median & $\overline{p \text { value }}$ & Mean HS & SEM & Median & $p$ value \\
\hline Normal testis & 49 & 0.0 & 0.0 & 0 & NA & 29.4 & 7.0 & 0 & NA & 0.0 & 0.0 & 0 & NA \\
\hline Germ cell tumours ${ }^{\mathrm{b}}$ & 207 & 13.5 & 2.9 & 0.0 & $<0.01$ & 213.4 & 6.2 & 220.0 & $<0.01$ & 51.6 & 4.5 & 20.0 & $<0.01$ \\
\hline Seminoma & 64 & 2.2 & 1.6 & 0 & $<0.01$ & 182.1 & 12.4 & 200 & $<0.01$ & 41.4 & 7.3 & 10 & $<0.01$ \\
\hline Embryonal carcinoma & 118 & 2.2 & 0.9 & 0 & $<0.01$ & 224.0 & 6.9 & 220 & $<0.01$ & 19.9 & 3.4 & 0 & $<0.01$ \\
\hline Yolk sac tumour & 30 & 14.0 & 6.7 & 0 & $<0.01$ & 202.4 & 20.4 & 210 & $<0.01$ & 87.4 & 15.0 & 50 & $<0.01$ \\
\hline Choriocarcinoma & 15 & 15.3 & 7.1 & 0 & $<0.01$ & 181.7 & 24.1 & 200 & $<0.01$ & 53.8 & 16.2 & 50 & $<0.01$ \\
\hline Teratoma & 41 & 56.0 & 11.6 & 20 & $<0.01$ & 186.9 & 13.2 & 180 & $<0.01$ & 103.4 & 10.6 & 90 & $<0.01$ \\
\hline GCNIS & 71 & 4.3 & 4.2 & 0 & $<0.01$ & 193.1 & 13.0 & 200 & $<0.01$ & 7.6 & 3.3 & 0 & $<0.01$ \\
\hline
\end{tabular}

Boldface $p$ value denotes statistical significance $<0.05$

NA Not applicable; GCNIS Germ cell neoplasia in situ; SEM Standard error of the mean; HS Histoscore

${ }^{a}$ Compared to normal testicular tissue

${ }^{\mathrm{b}}$ The highest NER expression in any histologic subtype in case of mixed GCTs

poor prognosis group, lung, liver and other non-pulmonary visceral metastases, as well as with increasing $\mathrm{S}$ stage. Primary extragonadal GCTs had higher XPA protein levels compared to primary TGCTs; however, this difference was not statistically significant. Higher ERCC1 expression correlated with IGCCCG risk group and S stage. XPF expression was not associated with any observed parameter (Table 2).

The median follow-up time was 81.8 months (0.4-235.8) for all patients and 92.9 months (7.1-235.8) for patients who survived. During follow-up, 28 patients died. All observed deaths were due to testicular cancer. Estimated 5-year OS was $87.1 \%$. Patients with low $X P A$ expression had significantly better OS than patients with high XPA expression (hazard ratio $[\mathrm{HR}]=0.38,95 \%$ confidence interval $[\mathrm{CI}]$ : 0.121.23, $p=0.0228$ ) (Fig. 1a). The differences were more pronounced in the non-seminomatous group and in patients with metastatic disease ( $\mathrm{HR}=0.36,95 \%$ CI: $0.11-1.19, p=$ 0.0189 and $\mathrm{HR}=0.34,95 \% \mathrm{CI}: 0.1-1.15, p=0.0102$, respectively). Similarly, OS was inversely associated with $E R C C 1$ $(\mathrm{HR}=0.35,95 \%$ CI: $0.03-3.56 p=0.1295)$ and $X P F(\mathrm{HR}=$ $0.65,95 \%$ CI: 0.26-1.64, $p=0.4250$ ) expression (Fig. $1 \mathrm{~b}$ and c, respectively), though these data were not statistically significant. An increase in combined expression of all three NER proteins (ERCC1 + XPF + XPA) was observed in nonseminomatous histological subtype, primary extragonadal tumour, IGCCCG poor prognosis group, > 3 metastatic sites, lung metastasis and increased $\mathrm{S}$ stage, and was associated with worse OS (HR $=0.36,95 \%$ CI: $0.12-1.09, p=0.0109$ ) (Table 3, Fig. 1d).

Multivariate analysis revealed that XPA protein level is significantly associated with OS independent of IGCCCG risk group (Table 4), indicating that XPA is promising IGCCCGindependent prognostic factor for OS in GCTs.

\section{The expression of the NER factors in GCT cell lines}

We wanted to further study the association between NER expression and prognosis for GCT patients in vitro by examining mRNA and protein levels of ERCC1, XPF and XPA in well-characterized CDDP-resistant and -sensitive GCT cell lines [23, 24]. As shown in Fig. 2a and Additional file 3: Figure S1A, XPA mRNA expression was significantly higher in all CDDP-resistant compared to -sensitive GCT cell lines, while ERCC1 mRNA expression levels were either unchanged or slightly higher in CDDP-resistant vs -sensitive lines (Fig. 2b and Additional file 3: Figure S1B). The picture is less clear for XPF expression; while CDDPresistant cell lines H12.1ODM and 1411HP showed a statistically significant increase in XPF expression compared with CDDP-sensitive cell lines, no difference was seen for the cell line 1777NRpmet (Fig. 2c and Additional file 3: Figure S1C).

Relative ERCC1, XPF and XPA protein expression levels in CDDP-resistant compared to -sensitive GCT cell lines are summarized in Fig. 3 and Additional file 4: Figure S2. With the exception of 1411HP vs NTERA-2 pairwise combination, the XPA protein levels were remarkably higher in CDDP-resistant compared to -sensitive GCT cell lines (Fig. 3a and Additional file 4: Figure S2A). Similarly, ERCC1 protein levels were elevated in CDDP-resistant compared with -sensitive GCT cell lines, however, this was less pronounced (Fig. $3 \mathrm{~b}$ and Additional file 4: Figure S2B). However, no direct correlation can be drawn from XPF protein levels and CDDPresistance (Fig. 3c and Additional file 4: Figure S2C). Together, these data suggest that overexpression of NER factors, particularly $X P A$, correlates with response to CDDP, mirroring our clinical data. Based on our findings, we propose that one of the fundamental mechanisms of CDDP resistance in GCTs is up-regulation of XPA and, by inference, the whole NER pathway.

\section{The role of XPA phosphorylation in establishing CDDP resistance}

XPA has previously been shown to interact with, and be phosphorylated by, ataxia telangiectasia-mutated and 
Table 2 Patient's characteristics according to the expression of individual NER proteins in primary tumour $(n=207)$

\begin{tabular}{|c|c|c|c|c|c|c|c|c|c|c|c|c|c|}
\hline \multirow[b]{2}{*}{ Variable } & \multirow[b]{2}{*}{$N$} & \multicolumn{4}{|l|}{ ERCC1 } & \multicolumn{4}{|l|}{ XPF } & \multicolumn{4}{|l|}{ XPA } \\
\hline & & Mean HS & SEM & Median & $p$ value & Mean HS & SEM & Median & $p$ value & Mean HS & SEM & Median & $p$ value \\
\hline All patients & 207 & 13.5 & 2.9 & 0.0 & NA & 213.4 & 6.2 & 220.0 & NA & 51.6 & 4.5 & 20.0 & NA \\
\hline \multicolumn{14}{|l|}{ Histology } \\
\hline Seminoma & 38 & 1.9 & 6.8 & 0.0 & 0.0807 & 163.0 & 13.8 & 200.0 & ${ }^{* * *} 0.0015$ & 31.9 & 10.5 & 5.0 & ${ }^{*} 0.0196$ \\
\hline Non-seminoma & 169 & 15.9 & 3.2 & 0.0 & & 224.6 & 6.6 & 240.0 & & 56.0 & 5.0 & 30.0 & \\
\hline \multicolumn{14}{|l|}{ Tumour primary } \\
\hline Primary TGCTs & 200 & 13.5 & 2.9 & 0.0 & 0.4771 & 212.2 & 6.2 & 210.0 & 0.2250 & 50.8 & 4.6 & 20.0 & 0.0676 \\
\hline Extragonadal GCTs & 7 & 12.9 & 15.6 & 0.0 & & 248.3 & 35.6 & 300.0 & & 79.2 & 26.3 & 80.0 & \\
\hline \multicolumn{14}{|l|}{ IGCCCG risk group } \\
\hline Good prognosis & 158 & 9.9 & 3.3 & 0.0 & ${ }^{*} 0.0322$ & 210.5 & 7.0 & 215.0 & 0.3983 & 44.7 & 5.0 & 10.0 & ${ }^{* * *} 0.0002$ \\
\hline Intermediate & 23 & 21.3 & 8.5 & 0.0 & & 239.8 & 18.2 & 265.0 & & 60.2 & 13.1 & 50.0 & \\
\hline Poor prognosis & 26 & 28.2 & 8.2 & 0.0 & & 206.0 & 17.4 & 200.0 & & 91.8 & 13.4 & 75.0 & \\
\hline \multicolumn{14}{|c|}{ Number of metastatic sites } \\
\hline 0 & 54 & 13.4 & 5.6 & 0.0 & 0.5566 & 216.3 & 11.9 & 210.0 & 0.8651 & 49.3 & 8.7 & 20.0 & 0.0628 \\
\hline 1 to 2 & 124 & 11.9 & 3.7 & 0.0 & & 210.3 & 8.0 & 210.0 & & 47.0 & 5.7 & 20.0 & \\
\hline$>3$ & 29 & 20.6 & 7.9 & 0.0 & & 220.2 & 16.6 & 250.0 & & 82.5 & 13.0 & 55.0 & \\
\hline \multicolumn{14}{|c|}{ Retroperitoneal lymph nodes metastases } \\
\hline Absent & 61 & 13.4 & 5.3 & 0,0 & 0.5226 & 215.4 & 11.2 & 210.0 & 0.8157 & 53.9 & 8.3 & 20.0 & 0.7993 \\
\hline Present & 146 & 13.5 & 3.4 & 0.0 & & 212.4 & 7.4 & 220.0 & & 50.6 & 5.4 & 20.0 & \\
\hline \multicolumn{14}{|c|}{ Mediastinal lymph nodes metastases } \\
\hline Absent & 189 & 12.8 & 3.0 & 0.0 & 0.9408 & 213.3 & 6.5 & 215.0 & 0.9501 & 50.2 & 4.7 & 20.0 & 0.4597 \\
\hline Present & 18 & 21.2 & 10.0 & 0.0 & & 213.1 & 20.6 & 225.0 & & 72.7 & 16.6 & 75.0 & \\
\hline \multicolumn{14}{|l|}{ Lung metastases } \\
\hline Absent & 160 & 10.9 & 3.3 & 0.0 & 0.1664 & 208.6 & 7.0 & 205.0 & 0.1478 & 47.6 & 5.1 & 10.0 & ${ }^{*} 0.0252$ \\
\hline Present & 47 & 22.3 & 6.0 & 0.0 & & 229.2 & 12.8 & 257.5 & & 67.0 & 9.7 & 50.0 & \\
\hline \multicolumn{14}{|l|}{ Liver } \\
\hline Absent & 197 & 12.7 & 2.9 & 0.0 & 0.0510 & 213.0 & 6.3 & 210.0 & 0.8140 & 49.1 & 4.6 & 20.0 & ${ }^{* * *} 0.0037$ \\
\hline Present & 10 & 28.0 & 13.0 & 0.0 & & 219.0 & 27.7 & 250.0 & & 110.6 & 21.1 & 120.0 & \\
\hline \multicolumn{14}{|c|}{ Non-pulmonary visceral metastases } \\
\hline Absent & 194 & 13.2 & 3.0 & 0.0 & 0.2293 & 213.1 & 6.4 & 210.0 & 0.9441 & 49.0 & 4.6 & 20.0 & ${ }^{* * *} 0.0032$ \\
\hline Present & 13 & 16.5 & 11.4 & 0.0 & & 216.2 & 24.3 & 230.0 & & 101.4 & 19.1 & 70.0 & \\
\hline \multicolumn{14}{|l|}{ S stage } \\
\hline 0 & 78 & 9.3 & 4.6 & 0.0 & ${ }^{*} 0.0455$ & 198.9 & 9.7 & 200.0 & 0.3526 & 38.5 & 7.1 & 5.0 & ${ }^{* * *} 0.0004$ \\
\hline 1 & 78 & 6.9 & 4.6 & 0.0 & & 218.9 & 9.8 & 240.0 & & 51.6 & 7.1 & 20.0 & \\
\hline 2 & 29 & 29.7 & 7.5 & 0.0 & & 232.9 & 16.0 & 250.0 & & 61.9 & 12.1 & 50.0 & \\
\hline 3 & 16 & 36.6 & 10.1 & 0.0 & & 226.0 & 22.2 & 240.0 & & 102.3 & 16.2 & 100.0 & \\
\hline unknown & 6 & & & & & & & & & & & & \\
\hline
\end{tabular}

Boldface $p$ value denotes statistical significance $<0.05:{ }^{*} p<0.05 ;{ }^{* *} p<0.01,{ }^{* * * *} p<0.005$

NA Not applicable; TGCT Testicular germ cell tumour; GCT Germ cell tumour; IGCCCG International Germ Cell Consensus Classification Group; HS Histoscore; SEM Standard error of the mean

Rad3-related (ATR) checkpoint kinase at S196 [32, 33], however the role of this event is still rather elusive. It is possible that this phosphorylation event, which requires Sirtuin 1-dependent deacetylation of XPA, leads to cytosolic-to-nuclear translocation and stabilization (by inhibiting ubiquitination and subsequent degradation) of XPA [34-37]. To further understand the role of XPA in the CDDP resistance mechanism in GCTs, we examined 


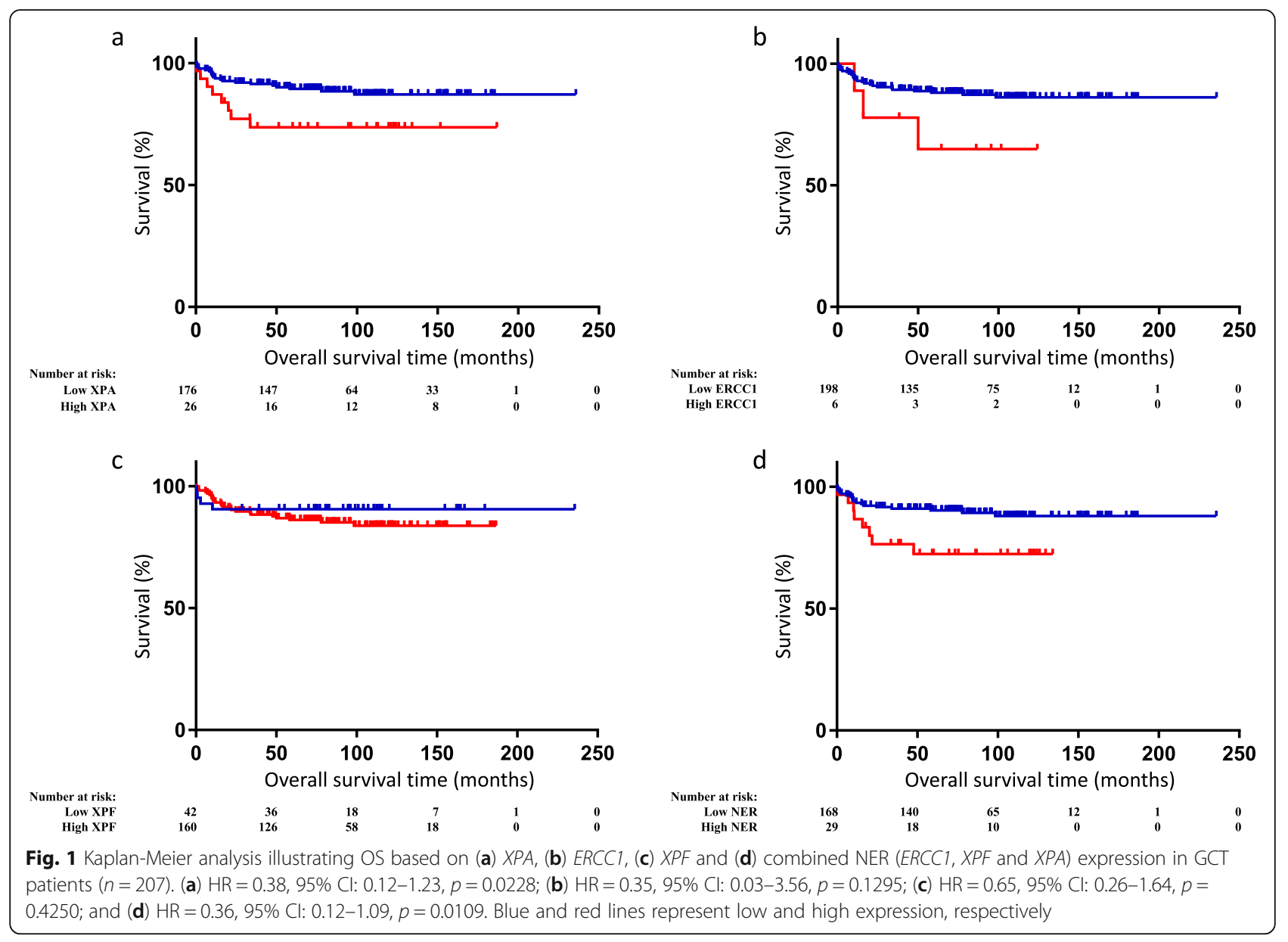

the possibility that S196 phosphorylation plays a role in this process.

While we observed a 3- to 4-fold increase in XPA protein in CDDP-resistant compared to -sensitive GCT cell lines (Fig. 3a), no difference was seen in XPA phosphorylation (Fig. 4a). CDDP treatment led to an increase in XPA phosphorylation, in a similar manner to UV exposure [32], however there was little difference in this response between CDDP-resistant and -sensitive cell lines tested (Fig. 4b). These data indicate that (i) XPA phosphorylation does not have an impact on increase of the total XPA protein level, (ii) CDDP-induced DNA damage may represent a relatively weak signal leading to ATR-mediated XPA phosphorylation, and (iii) XPA phosphorylation does not play a role in the CDDP resistance mechanism in GCTs.

\section{Discussion}

Resistance to CDDP poses a serious problem in patient management as it leads to poor prognosis in many malignancies. GCTs are among the most CDDP-sensitive malignity, and therefore represent a highly valuable model for the study of CDDP resistance mechanism.
CDDP induces a wide variety of DNA lesions, and therefore cellular response to this drug is multifaceted. Central to the repair of such lesions is the Fanconi anemia pathway, a highly complex DDR and repair pathway that coordinates the action of a plethora of DNA repair mechanisms, including NER, required to remove CDDP-induced DNA damage. NER requires many DNA repair enzymes that act sequentially to remove bulky DNA adducts, such as ICLs. NER contributes significantly to the cellular response to ICL-inducing agents, such as CDDP, widely used in anti-cancer chemotherapy regimens, thereby highlighting the clinical importance of this repair pathway for therapeutic outcome.

It has been hypothesized that CDDP sensitivity in GCTs may be caused by decreased capacity of NER, as a consequence of a reduced expression of its key components. Indeed, the expression of XPA and components of the ERCC1-XPF nuclease have been found to be lower in cell lines derived from GCTs compared to those from other tumour types [21,22]. This difference, however, does not appear to affect the cells ability to perform NER [38].

The purpose of the present study was to determine the expression levels of the key NER factors, ERCC1, 
Table 3 Patient's characteristics according to the expression of combined NER (ERCC1, XPF and XPA) in primary tumour ( $n=207$ )

\begin{tabular}{|c|c|c|c|c|c|}
\hline \multirow[b]{2}{*}{ Variable } & \multirow[b]{2}{*}{$N$} & \multicolumn{4}{|c|}{ Combined NER } \\
\hline & & Mean HS & SEM & Median & $p$ value \\
\hline All patients & 207 & 282.6 & 10.1 & 280.0 & NA \\
\hline \multicolumn{6}{|l|}{ Histology } \\
\hline Seminoma & 38 & 202.2 & 22.9 & 205.0 & \multirow[t]{2}{*}{${ }^{* * *} 0.0004$} \\
\hline Non-seminoma & 169 & 300.6 & 10.8 & 300.0 & \\
\hline \multicolumn{6}{|l|}{ Tumour primary } \\
\hline Primary TGCTs & 200 & 279.9 & 10.2 & 270.0 & \multirow[t]{2}{*}{${ }^{*} 0.0500$} \\
\hline Extragonadal GCTs & 7 & 387.0 & 63.4 & 360.0 & \\
\hline \multicolumn{6}{|l|}{ IGCCCG risk group } \\
\hline Good prognosis & 158 & 266.4 & 11.3 & 260.0 & \multirow[t]{3}{*}{${ }^{* *} 0.0062$} \\
\hline Intermediate & 23 & 321.3 & 29.1 & 320.0 & \\
\hline Poor prognosis & 26 & 358.3 & 30.4 & 345.0 & \\
\hline \multicolumn{6}{|c|}{ Number of metastatic sites } \\
\hline 0 & 54 & 279.0 & 19.2 & 250.0 & \multirow[t]{3}{*}{${ }^{*} 0.0471$} \\
\hline 1 to 2 & 124 & 271.0 & 12.9 & 270.0 & \\
\hline$>3$ & 29 & 348.3 & 28.8 & 330.0 & \\
\hline \multicolumn{6}{|c|}{ Retroperitoneal lymph nodes metastases } \\
\hline Absent & 61 & 282.7 & 18.3 & 250.0 & \multirow[t]{2}{*}{0.6121} \\
\hline Present & 146 & 282.5 & 12.2 & 287.5 & \\
\hline \multicolumn{6}{|c|}{ Mediastinal lymph nodes metastases } \\
\hline Absent & 189 & 277.9 & 10.5 & 270.0 & \multirow[t]{2}{*}{0.1142} \\
\hline Present & 18 & 339.7 & 36.6 & 310.0 & \\
\hline \multicolumn{6}{|l|}{ Lung metastases } \\
\hline Absent & 160 & 268.8 & 11.3 & 252.5 & \multirow[t]{2}{*}{${ }^{* * *} 0.0048$} \\
\hline Present & 47 & 331.9 & 21.4 & 325.0 & \\
\hline \multicolumn{6}{|l|}{ Liver } \\
\hline Absent & 197 & 278.5 & 10.3 & 270.0 & \multirow[t]{2}{*}{0.0584} \\
\hline Present & 10 & 368.3 & 47.1 & 350.0 & \\
\hline \multicolumn{6}{|c|}{ Non-pulmonary visceral metastases } \\
\hline Absent & 194 & 278.3 & 10.4 & 270.0 & \multirow[t]{2}{*}{0.0661} \\
\hline Present & 13 & 354.5 & 42.7 & 345.0 & \\
\hline \multicolumn{6}{|l|}{ S stage } \\
\hline 0 & 78 & 246.7 & 15.5 & 232.5 & \multirow[t]{5}{*}{${ }^{* * *} 0.0004$} \\
\hline 1 & 78 & 283.1 & 15.8 & 285.0 & \\
\hline 2 & 29 & 335.0 & 26.3 & 345.0 & \\
\hline 3 & 16 & 385.7 & 36.5 & 362.5 & \\
\hline unknown & 6 & & & & \\
\hline
\end{tabular}

Boldface $p$ value denotes statistical significance $<0.05:{ }^{*} p<0.05 ;{ }^{* *} p<0.01,{ }^{* * *} p<0.005$

NA Not applicable; TGCT Testicular germ cell tumour; GCT Germ cell tumour; IGCCCG International Germ Cell

Consensus Classification Group; HS Histoscore; SEM Standard error of the mean

$\mathrm{XPF}$ and XPA, in a substantial group of GCTs displaying a variety of histological subtypes. We show significantly increased expression of these factors in all histological subtypes of GCTs compared to normal testicular tissues, which is consistent with previously reported data [19].
Notably, while XPF expression was consistent across all GCT histological subtypes, expression of ERCC1 and $X P A$ varied greatly, with increased expression in the most differentiated TE, suggesting that the process of differentiation of germ cells to somatic structures may 
Table 4 Prognostic value of XPA expression

\begin{tabular}{|c|c|c|}
\hline \multirow[t]{2}{*}{ Variable } & \multicolumn{2}{|l|}{ OS } \\
\hline & $\begin{array}{l}\text { Univariate analysis } \\
\mathrm{HR}(95 \% \mathrm{Cl}) \\
p \text { value }\end{array}$ & $\begin{array}{l}\text { Multivariate analysis } \\
\text { HR }(95 \% \mathrm{Cl}) \\
p \text { value }\end{array}$ \\
\hline \multicolumn{3}{|l|}{ XPA expression } \\
\hline Low vs high & $\begin{array}{l}0.38(0.12-1.23) \\
p=\mathbf{0 . 0 2 3}\end{array}$ & $\begin{array}{l}0.42(0.18-1.01) \\
p=0.053\end{array}$ \\
\hline \multicolumn{3}{|l|}{ IGCCCG risk group } \\
\hline Good vs intermediate/poor & $\begin{array}{l}0.12(0.05-0.30) \\
p<\mathbf{0 . 0 0 0 0 1}\end{array}$ & $\begin{array}{l}0.11(0.05-0.26) \\
p=\mathbf{0 . 0 0 0 1}\end{array}$ \\
\hline
\end{tabular}

OS overall survival, $H R$ hazard ratio, $C I$ confidence interval, IGCCCG International Germ Cell

Consensus Classification Group

Boldface $p$ value denotes statistical significance $<0.05$

require NER factors. These mature TE are among the most CDDP-resistant histological subtypes.

We demonstrate the prognostic value of XPA expression on OS. In addition, we disclose a statistically significant correlation between the increased XPA expression and poor prognostic features in GCTs, including nonseminomatous histology, the IGCCCG poor prognosis group, presence of lung, liver and/or other nonpulmonary visceral metastases and high serum tumour markers. No other NER factor examined showed such a strong correlation with clinical-pathological characteristics in GCTs, although the whole NER pathway disclosed better associations compared to XPA alone. The question now remains whether single NER factors or a combination of many NER factors would provide more precise clinical information, as these two options may not lead to the same treatment outcomes.

XPA has numerous binding partners (reviewed in [11]) and is known to exhibit NER-independent cellular functions, including a role in bi-directional transcriptional change in a subset of genes [39]. The phenotype of
XPA-deficient cells would also suggest a critical role for XPA outside NER [40]. Of these functions, regulation of steroid hormone metabolism may be of great importance in GCTs. Having a regulatory role in metabolism of testosterone, XPA may contribute to pathological imbalance of the hormone during early (fetal) development, resulting in GCTs in later developmental stages. Indeed, higher testosterone levels detected at birth were found to be associated with increased GCT risk among adolescents (15-19 years) [41]. XPA is involved in nuclearmitochondrial crosstalk that is critical for the maintenance of mitochondrial homeostasis [40]. Biochemically functional mitochondria are critical for the synthesis of pregnenolone, a precursor for steroid hormones. XPAmediated control of mitochondrial health may, therefore, be a mechanism contributing to the development and progression of GCTs. Studies into any association between XPA and testosterone levels would be worthwhile.

ERCC1 has previously been shown to influence CDDP sensitivity in GCTs [18]. Here, we confirm that increased expression of ERCC1 correlates with poor prognosis and an increased $S$ stage of disease. However, we did not find any statistically significant correlation between ERCC1 expression and OS, in agreement with previously published data [18]. Therefore, ERCC1 on its own does not seem to be a reliable prognostic marker in GCTs.

The CDDP response in GCT patients and cell lines are both highly dependent on the expression levels of NER factors and GCT cell lines can, therefore, be used as a reliable model for studying CDDP resistance mechanisms. Herein, we revealed that the levels of ERCC1, XPF and XPA protein correspond with expression and not protein stability. We ruled out a possibility that S196 phosphorylation significantly influences the resulting XPA protein levels.
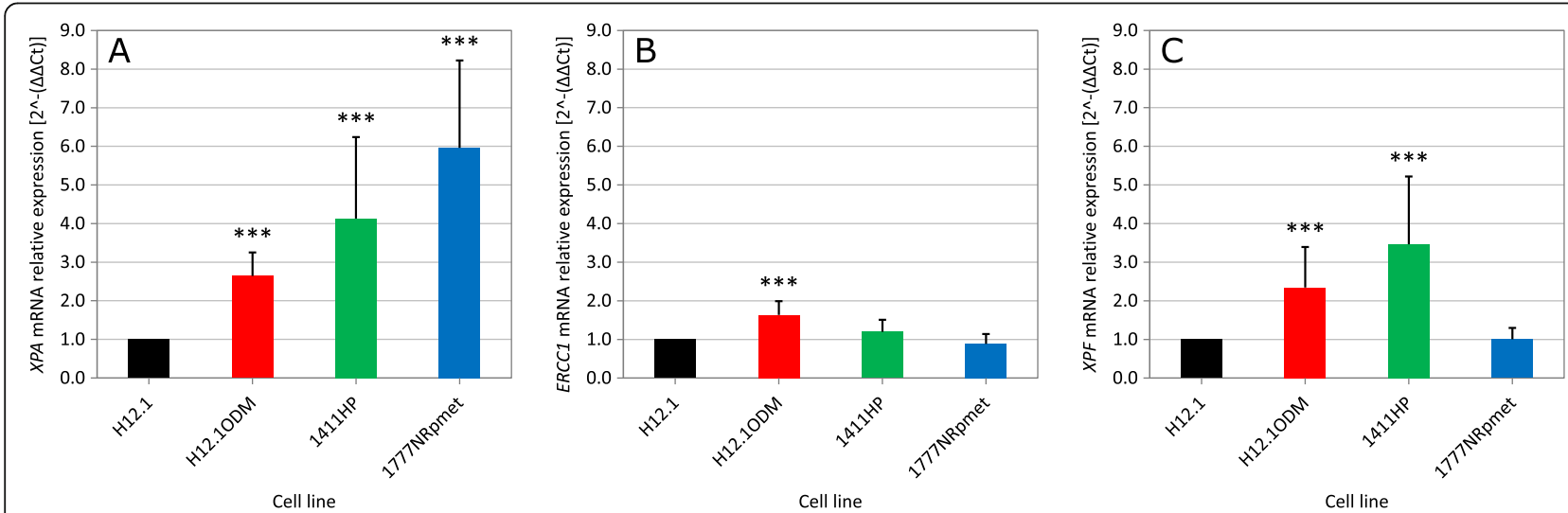

Fig. 2 Comparison of the (a) XPA, (b) ERCC1 and (c) XPF mRNA expression between CDDP-resistant (H12.10DM, 1411HP and 1777NRpmet) and -sensitive (H12.1) GCT cell lines. Error bars represent the standard deviation of three technical replicates of three biological replicates. ${ }^{*} p \leq 0.01,{ }^{* *}$ $p \leq 0.005$, *** $p \leq 0.001$ 

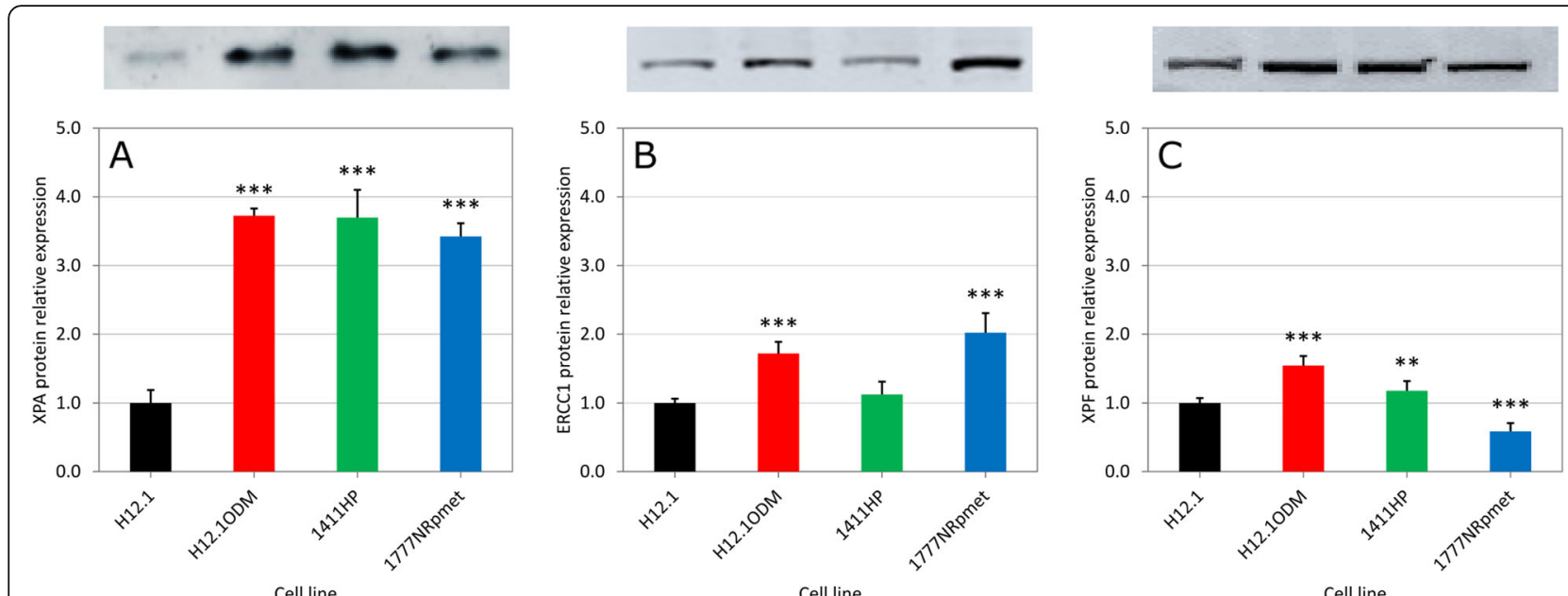

Fig. 3 Comparison of the (a) XPA, (b) ERCC1 and (c) XPF protein expression between CDDP-resistant (H12.1ODM, 1411HP and 1777NRpmet) and -sensitive (H12.1) GCT cell lines. Upper panels show representative Western blots. Lower panels (graphs) are quantitative analyses of three technical replicates of three biological replicates with error bars representing the standard deviation. ${ }^{*} p \leq 0.01,{ }^{* *} p \leq 0.005,{ }^{* * *} p \leq 0.001$

Undoubtedly, further work is required to fully understand the mechanisms driving NER expression in CDDP resistance. Once these mechanisms are sufficiently understood, their therapeutic targeting could be investigated.

\section{Conclusions}

We show significantly higher expression of the three key NER proteins, ERCC1, XPF and XPA, in GCTs compared to normal testicular tissue. Moreover, we report a correlation between higher XPA expression in primary

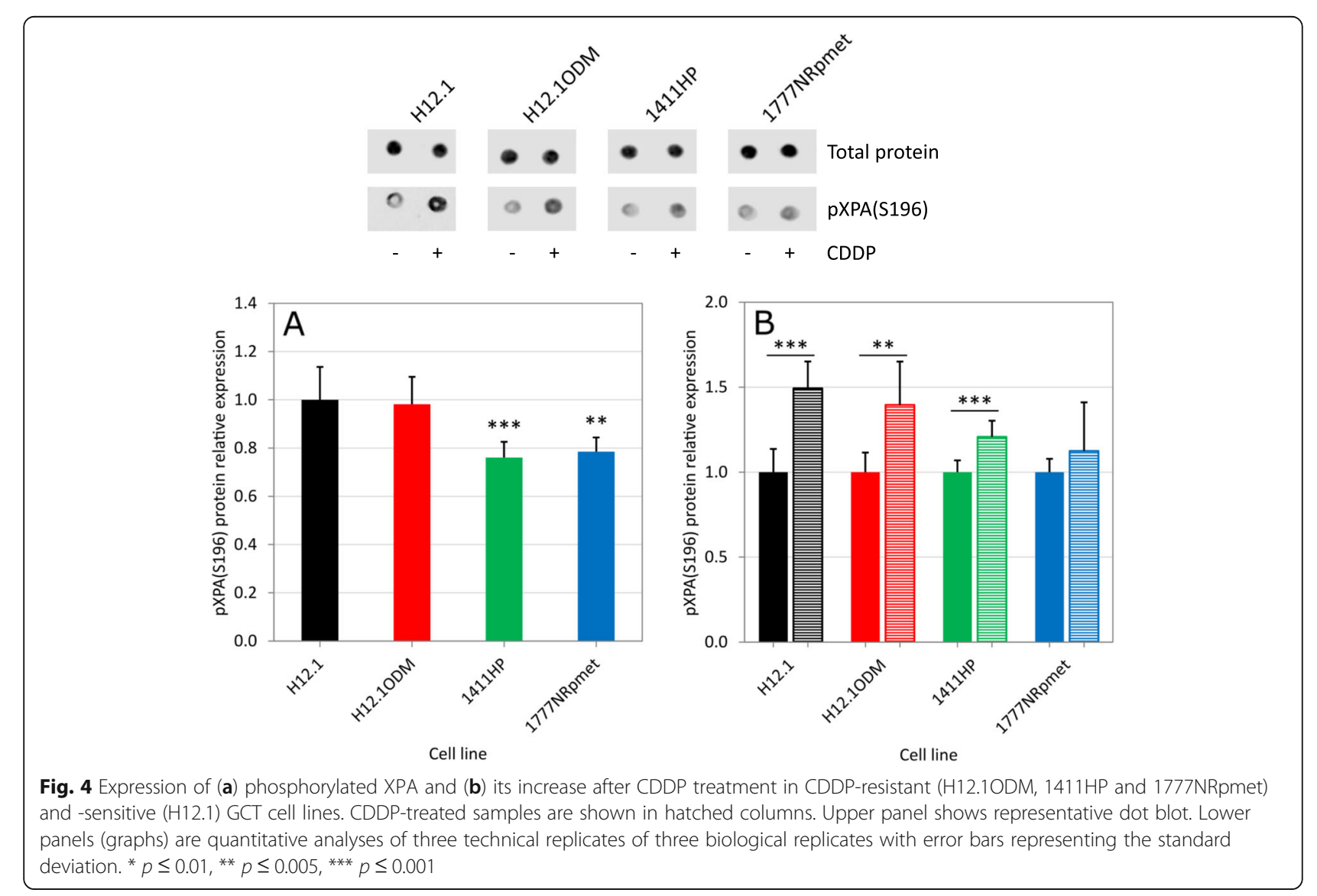


tumour tissues and inferior outcome in GCT patients: $X P A$ expression is higher in patients with more advanced disease and poor prognostic features, suggesting a possibility that its increased level may ensure CDDP chemoresistance in primary GCTs and subsequent tumour dissemination and disease progression. Importantly, a correlation between XPA expression and CDDPbased treatment response obtained using patients' samples was well-mirrored in GCT cell lines. In contrast to what we expected, S196 phosphorylation does not seem to have an essential role in ensuring high XPA levels in CDDP-resistant GCT cell lines. Instead, accumulation of XPA protein is achieved by up-regulation of expression. In summary, we propose that the expression level of $\mathrm{XPA}$, as well as NER as a whole, represent additional prognostic biomarkers for stratifying GCT patients to optimize the disease management. In addition, they potentially constitute promising therapeutic targets in this malignity.

\section{Supplementary information}

Supplementary information accompanies this paper at https://doi.org/10. 1186/s12885-019-6496-1.

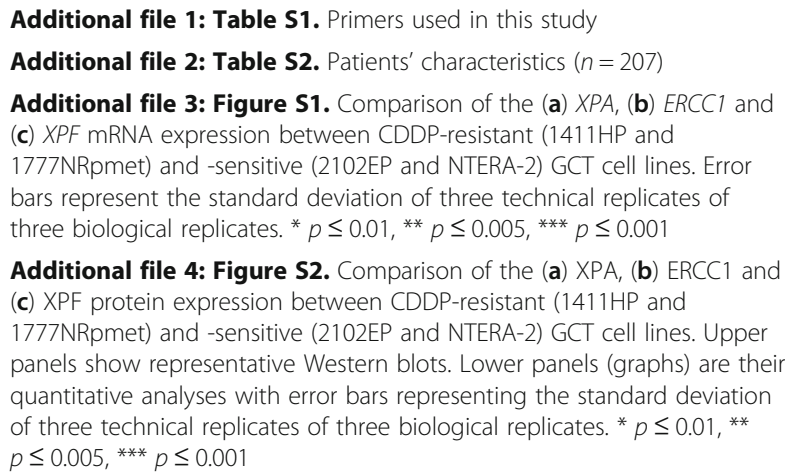

Additional file 4: Figure S2. Comparison of the (a) XPA, (b) ERCC1 and (c) XPF protein expression between CDDP-resistant (1411 HP and 1777NRpmet) and -sensitive (2102EP and NTERA-2) GCT cell lines. Upper panels show representative Western blots. Lower panels (graphs) are their quantitative analyses with error bars representing the standard deviation of three technical replicates of three biological replicates. ${ }^{*} p \leq 0.01,{ }^{* *}$ $p \leq 0.005,{ }^{* * *} p \leq 0.001$

\section{Abbreviations}

AFP: a-fetoprotein; ANOVA: Analysis of variance; ATR: Ataxia telangiectasiamutated and Rad3-related; CDDP: Cisplatin; Cl: Confidence interval; DDR: DNA damage response; ERCC1: Excision repair cross-complementation group 1; FBS: Fetal bovine serum; GCNIS: Germ cell neoplasia in situ; GCT: Germ cell tumour; HR: Hazard ratio; HS: Histoscore; ICL: Interstrand cross-link; IGCCCG: International Germ Cell Cancer Collaborative Group; LDH: Lactate dehydrogenase; NER: Nucleotide excision repair; OS: Overall survival; PBS: Phosphate-buffered saline; PGK1: Phosphoglycerate kinase 1; PXPA(S196): XPA phosphorylated at serine 196; qRT-PCR: Quantitative reverse transcription polymerase chain reaction; RT: Room temperature; SEM: Standard error of the mean; TBS: Tris-buffered saline; TGCT: Testicular germ cell tumour; XPA: Xeroderma pigmentosum complementation group $\mathrm{A}$; XPF: Xeroderma pigmentosum complementation group $\mathrm{F}$;

XPG: Xeroderma pigmentosum complementation group G; $\beta$-HCG: $\beta$-human chorionic gonadotropin

\section{Acknowledgements}

GCT cell lines used in this study were kindly provided by Dr. T. Mueller (Martin Luther University of Halle-Wittenberg, Halle, Germany). We would like to acknowledge our collaborators from several Departments of Pathology within Slovakia, M. Antol, J. Benko, D. Danis, D. Durcansky, P. Fiala, S. Galbavy, M. Gogora, P. Hudcovsky, J. Macuch, P. Martanovic, F. Ondrias, L. Plank, and
M. Svajdler. We also thank to Mrs. D. Jantekova from the Population Registry of the Slovak Republic for her help with updating patients' database. Finally, we wish to acknowledge Mrs. Z. Pekova for administration support and E. Klincova for excellent technical assistance. All the acknowledged people permitted naming them herein.

\section{Authors' contributions}

ZC, DJ, LBP, MC1 (Miroslav Chovanec) and MM conceived and designed the study. ZC, VM, DJ, LBP, ZS, JR, LH, KM, KR, KK1 (Katarina Kalavska), KK2 (Karol Kajo), DS, PB, MC2 (Michal Chovanec), JM and MM acquired data. ZC, MC1, DJ, LBP, JR, MM, KK1, KK2, TAW and MC2 analyzed and interpreted data. $M C 1, M M$ and $Z C$ wrote first draft of the manuscript and VM, DJ, LBP, ZS, JR, $K M, M C 2, D S, K K 1, K K 2, P B$, TAW and JM critically revised the manuscript. MM ZC, DJ and JR performed statistical analysis. MC1, MM, JM and DJ obtained funding. LH contributed also as an administrative and technical support. MC1 and MM supervised the whole study. All authors read and approved the final manuscript.

\section{Funding}

This work was supported by the Slovak Research and Development Agency under contracts No. APW-0016-11, APW-15-0086 and APW-17-0384, VEGA Grant Agency of the Slovak Republic (grants No. 2/0108/17, 1/0043/18 and 2/0053/19) and the Ministry of Health of the Slovak Republic (grant No. 2019/57-BMCSAV-1). The funding bodies played no role in the design of the study and collection, analysis, and interpretation of data and in writing the manuscript. The sponsors played no direct role in the study.

\section{Availability of data and materials}

All data generated or analysed during this study are included in this published article.

\section{Ethics approval and consent to participate}

This study (IZLO 1) was approved by the Ethics Committee of the National Cancer Institute on the 2nd of February 2010, and waiver of informed consent was granted according to the Biomedical Research Act No. 576/ 2004 Z.z. of the Slovak Republic. None of the cell lines required ethics approval for its use.

\section{Consent for publication}

Not applicable.

\section{Competing interests}

All of the authors declare that they have no conflict of interest.

\section{Author details}

${ }^{1}$ Department of Pathology, Faculty of Medicine, Comenius University, Bratislava, Slovakia. ${ }^{2} 1$ st Department of Oncology, Faculty of Medicine, Comenius University, Bratislava, Slovakia. ${ }^{3}$ St. Elisabeth Cancer Institute, Bratislava, Slovakia. ${ }^{4}$ Department of Genetics, Cancer Research Institute, Biomedical Research Center, University Science Park for Biomedicine, Slovak Academy of Sciences, Bratislava, Slovakia. ${ }^{5}$ nd Department of Oncology, Faculty of Medicine, Comenius University, Bratislava, Slovakia. ${ }^{6}$ National

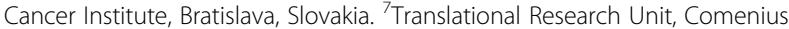
University, Bratislava, Slovakia. ${ }^{8}$ Department of Molecular Oncology, Cancer Research Institute, Biomedical Research Center, University Science Park for Biomedicine, Slovak Academy of Sciences, Bratislava, Slovakia. ${ }^{9}$ Faculty Hospital with Policlinics Skalica a.s., Skalica, Slovakia. ${ }^{10}$ Department of Biomedical and Life Sciences, Faculty of Health and Medicine, Lancaster University, Lancaster, UK.

Received: 13 February 2019 Accepted: 23 December 2019 Published online: 06 January 2020

\section{References}

1. Motzer RJ, Geller NL, Tan CC, Herr H, Morse M, Fair W, Sheinfeld J, Sogani P, Russo P, Bosl GJ. Salvage chemotherapy for patients with germ cell tumors. The Memorial Sloan-Kettering Cancer Center experience (1979-1989). Cancer. 1991;67(5):1305-10.

2. Einhorn LH. General motors Cancer research prizewinners laureates lectures. Charles F. Kettering prize. Clinical trials in testicular cancer. Cancer. 1993; 71(10):3182-4. 
3. Motzer RJ, Sheinfeld J, Mazumdar M, Bains M, Mariani T, Bacik J, Bajorin D, Bosl GJ. Paclitaxel, ifosfamide, and cisplatin second-line therapy for patients with relapsed testicular germ cell cancer. J Clin Oncol. 2000;18(12):2413-8.

4. Mardiak J, Salek T, Sycova-Mila Z, Obertova J, Hlavata Z, Mego M, Reckova M, Koza I. Gemcitabine plus cisplatine and paclitaxel (GCP) in second-line treatment of germ cell tumors (GCT): a phase II study. Neoplasma. 2005; 52(3):243-7.

5. Kollmannsberger C, Nichols C, Bokemeyer C. Recent advances in management of patients with platinum-refractory testicular germ cell tumors. Cancer. 2006;106(6):1217-26.

6. Cullen M. Surveillance or adjuvant treatments in stage 1 testis germ-cell tumours. Ann Oncol. 2012;23(Suppl 10):x342-8.

7. Kopp HG, Kuczyk M, Classen J, Stenzl A, Kanz L, Mayer F, Bamberg M, Hartmann JT. Advances in the treatment of testicular cancer. Drugs. 2006; 66(5):641-59.

8. O'Connor PM, Kohn KW. Comparative pharmacokinetics of DNA lesion formation and removal following treatment of L1210 cells with nitrogen mustard. Cancer Com. 1990;2(12):387-94.

9. Duxin JP, Walter JC. What is the DNA repair defect underlying Fanconi anemia? Curr Opin Cell Biol. 2015;37:49-60.

10. Schärer OD. Nucleotide excision repair in eukaryotes. Cold Spring Harb Perspect Biol. 2013;5(10):a012609.

11. Sugitani N, Sivley RM, Perry KE, Capra JA, Chazin WJ. XPA: a key scaffold for human nucleotide excision repair. DNA Repair (Amst). 2016;44:123-35.

12. Spivak G. Nucleotide excision repair in humans. DNA Repair (Amst). 2015;36: 13-8.

13. Friboulet L, Olaussen KA, Pignon JP, Shepherd FA, Tsao MS, Graziano S, Kratzke $R$, Douillard JY, Seymour L, Pirker R, et al. ERCC1 isoform expression and DNA repair in non-small-cell lung cancer. N Engl J Med. 2013;368(12):1101-10.

14. Handra-Luca A, Hernandez J, Mountzios G, Taranchon E, Lacau-St-Guily J, Soria JC, Fouret P. Excision repair cross complementation group 1 immunohistochemical expression predicts objective response and cancerspecific survival in patients treated by cisplatin-based induction chemotherapy for locally advanced head and neck squamous cell carcinoma. Clin Cancer Res. 2007;13(13):3855-9.

15. Dabholkar MD, Bostick-Bruton F, Weber C, Bohr VA, Egwuagu C, Reed E. ERCC1 and ERCC2 expression in malignant tissues from ovarian cancer patients. J Nat Cancer Inst. 1992;84(19):1512-7.

16. Metzger R, Leichman CG, Danenberg KD, Danenberg PV, Lenz HJ, Hayashi K, Groshen S, Salonga D, Cohen H, Laine L, et al. ERCC1 mRNA levels complement thymidylate synthase mRNA levels in predicting response and survival for gastric cancer patients receiving combination cisplatin and fluorouracil chemotherapy. J Clin Oncol. 1998;16(1):309-16.

17. Bellmunt J, Paz-Ares L, Cuello M, Cecere FL, Albiol S, Guillem V, Gallardo E, Charles J, Mendez P, de la Cruz JJ, et al. Gene expression of ERCC1 as a novel prognostic marker in advanced bladder cancer patients receiving cisplatin-based chemotherapy. Ann Oncol. 2007;18(3):522-8.

18. Mendoza J, Martinez J, Hernandez C, Perez-Montiel D, Castro C, FabianMorales E, Santibanez M, Gonzales-Barrios R, Diaz-Chavez J, Andonegui MA, et al. Association between ERCC1 and XPA expression and polymorphisms and the response to cisplatin in testicular germ cell tumours. Br J Cancer. 2013;109(1):68-75.

19. Köberle B, Brenner W, Albers A, Usanova S, Thuroff JW, Kaina B. ERCC1 and XPF expression in human testicular germ cell tumors. Oncol Rep. 2010;23(1): 223-7.

20. Honecker F, Mayer F, Stoop H, Oosterhuis JW, Koch S, Bokemeyer C, Looijenga LH. Xeroderma pigmentosum group a protein and chemotherapy resistance in human germ cell tumors. Lab Investig. 2003; 83(10):1489-95.

21. Welsh C, Day R, McGurk C, Masters JR, Wood RD, Köberle B. Reduced levels of XPA, ERCC1 and XPF DNA repair proteins in testis tumor cell lines. Int J Cancer. 2004;110(3):352-61.

22. Köberle B, Masters JRW, Hartley JA, Wood RD. Defective repair of cisplatininduced DNA damage caused by reduced XPA protein in testicular germ cell tumours. Curr Biol. 1999;9(5):273-6.

23. Mueller T, Mueller LP, Luetzkendorf J, Voigt W, Simon H, Schmoll HJ. Loss of Oct-3/4 expression in embryonal carcinoma cells is associated with induction of cisplatin resistance. Tumour Biol. 2006;27(2):71-83.

24. Schaffrath J, Schmoll HJ, Voigt W, Muller LP, Muller-Tidow C, Mueller T. Efficacy of targeted drugs in germ cell cancer cell lines with differential cisplatin sensitivity. PLoS One. 2017;12(6):e0178930.
25. Casper J, Schmoll HJ, Schnaidt U, Fonatsch C. Cell lines of human germinal cancer. Int J Androl. 1987;10(1):105-13.

26. Vogelzang NJ, Bronson D, Savino D, Vessella RL, Fraley EF. A human embryonal-yolk sac carcinoma model system in athymic mice. Cancer. 1985; 55(11):2584-93.

27. Bronson D, Vessella R, Fraley E. Differentiation potential of human embryonal carcinoma cell lines. Cell Differentiation. 1984;15(2-4):129-32.

28. Moch H, Cubilla AL, Humphrey PA, Reuter VE, Ulbright TM. The 2016 WHO classification of tumours of the urinary system and male genital organs-part a: renal, penile, and testicular tumours. Eur Urol. 2016;70(1):93-105.

29. Ulisse S, Baldini E, Mottolese M, Sentinelli S, Gargiulo P, Valentina B, Sorrenti S, Di Benedetto A, De Antoni D, D'Armiento M. Increased expression of urokinase plasminogen activator and its cognate receptor in human seminomas. BMC Cancer. 2010;10:151.

30. Mego M, Cierna Z, Svetlovska D, Macak D, Machalekova K, Miskovska V, Chovanec M, Usakova V, Obertova J, Babal P, et al. PARP expression in germ cell tumours. J Clin Pathol. 2013;66(7):607-12.

31. Kirkegaard T, Edwards J, Tovey S, McGlynn LM, Krishna SN, Mukherjee R, Tam L, Munro AF, Dunne B, Bartlett JM. Observer variation in immunohistochemical analysis of protein expression, time for a change? Histopathology. 2006;48(7):787-94.

32. Wu X, Shell SM, Yang Z, Zou Y. Phosphorylation of nucleotide excision repair factor xeroderma pigmentosum group a by ataxia telangiectasia mutated and Rad3-related-dependent checkpoint pathway promotes cell survival in response to UV irradiation. Cancer Res. 2006;66(6):2997-3005.

33. Shell SM, Li Z, Shkriabai N, Kvaratskhelia M, Brosey C, Serrano MA, Chazin WJ, Musich PR, Zou Y. Checkpoint kinase ATR promotes nucleotide excision repair of UV-induced DNA damage via physical interaction with xeroderma pigmentosum group a. J Biol Chem. 2009;284(36):24213-22.

34. Li Z, Musich PR, Cartwright BM, Wang H, Zou Y. UV-induced nuclear import of XPA is mediated by importin-alpha4 in an ATR-dependent manner. PLoS One. 2013;8(7):e68297.

35. Lee TH, Park JM, Leem SH, Kang TH. Coordinated regulation of XPA stability by ATR and HERC2 during nucleotide excision repair. Oncogene. 2014;33(1): 19-25.

36. Musich PR, Li Z, Zou Y. Xeroderma pigmentosa group a (XPA), nucleotide excision repair and regulation by ATR in response to ultraviolet irradiation. Adv Exp Med Biol. 2017;996:41-54.

37. Jarrett SG, Carter KM, Bautista RM, He D, Wang C, D'Orazio JA. Sirtuin 1mediated deacetylation of XPA DNA repair protein enhances its interaction with ATR protein and promotes CAMP-induced DNA repair of UV damage. J Biol Chem. 2018;293(49):19025-37.

38. Köberle B, Roginskaya V, Zima KS, Masters JR, Wood RD. Elevation of XPA protein level in testis tumor cells without increasing resistance to cisplatin or UV radiation. Mol Carcinog. 2008;47(8):580-6.

39. Manandhar M, Lowery MG, Boulware KS, Lin KH, Lu Y, Wood RD. Transcriptional consequences of XPA disruption in human cell lines. DNA Repair (Amst). 2017:57:76-90

40. Fang EF, Scheibye-Knudsen M, Brace LE, Kassahun $H$, SenGupta T, Nilsen $H$, Mitchell JR, Croteau DL, Bohr VA. Defective mitophagy in XPA via PARP-1 hyperactivation and NAD(+)/SIRT1 reduction. Cell. 2014;157(4):882-96.

41. Morimoto LM, Zava D, McGlynn KA, Stanczyk FZ, Kang AY, Ma X, Wiemels J, Metayer C. Neonatal hormone concentrations and risk of testicular germ cell tumors (TGCT). Cancer Epidemiol Biomark Prev. 2018;27(4):488-95.

\section{Publisher's Note}

Springer Nature remains neutral with regard to jurisdictional claims in published maps and institutional affiliations. 